\title{
TINJAUAN ASPEK KEAMANAN DAN KERAHASIAAN DOKUMEN REKAM MEDIS DI RUANG FILLING RUMAH SAKIT KHUSUS (RSK) PARU MEDAN TAHUN 2018
}

\author{
1. Puput Melati Hutauruk; ${ }^{2}$ Widya Tri Astuti \\ 1. Dosen APIKES Imelda, Jalan Bilal Nomor 52 Medan; ${ }^{2}$ Alumni APIKES Imelda \\ E-mail: ${ }^{\prime}$ Puputmelati.pm71@gmail.com
}

\begin{abstract}
ABSTRAK
Keamanan dan kerahasiaan merupakan faktor yang sangat penting dalam pengelolaan dokumen rekam medis.Keamanan dan kerahasiaan rekam medis di RSK Paru Medan belum terjaga. Masih ada selain petugas rekam medis yang keluar masuk ruang filling dan dokumen rekam medis yang hilang. Untuk mengetahui aspek keamanan dari segi aspek fisik, biologis dan kimiawi dan aspek kerahasiaan dokumen rekam medis di ruang filling di RSK Paru Medan.Jenis penelitian yang digunakan adalah deskriftif kualitatif dengan menggunakan metode observasi.Subjek penelitian yaitu 63 dokumen rekam medis.Objek penelitian dokumen rekam medis dan ruang filling.Instrumen penelitian data adalah pedoman observasi, alat pengukur suhu kelembapan, Check list.Analisa data adalah deskriptif.Hasil penelitian menunjukan dari segi aspek fisik tinta yang digunakan warna hitam sudah seragam.Kertas yang digunakan ukuran A4 berat 70 gram.Tidak adanya AC, APAR, tracer dan kamfer.Masih ada selain petugas rekam medis yang keluar masuk ke ruang filling sehingga dokumen rekam medis hilang.Pasien membawa sendiri dokumen rekam medisnya.Aspek biologis adanya jamur, kutu buku, dan serangga seperti rayap, kecoa, dan tikus.Aspek kimiawi adanya petugas rekam medis makan/minum di ruang rekam medis.Aspek kerahasiaanya masih ada petugas rekam medis yang masuk ke filling rekam medik dan masih ditemukan dokumen rekam medis yang di bawa pasien/hilang.Diharapkan pihak rumah sakit memenuhi fasilitas seperti APAR, AC, kamferdan melakukan pemeliharaan kebersihan di ruang penyimpanan.Sebaiknya dokumen rekam medis diantarkan oleh petugas distribusi.
\end{abstract}

Kata Kunci: Keamanan, kerahasiaan, dokumen rekam medis.

\section{PENDAHULUAN}

Rekam medis adalah berkas yang berisikan catatan dan dokumen tentang identitas pasien, pemeriksaan, pengobatan, tindakan dan pelayanan lain kepada pasien pada sarana pelayanan kesehatan Peraturan Menteri Kesehatan No.269/MENKES/III/2 008 tentang rekam medis, pasal 10 ayat pasal 10 ayat (1) bahwa isi berkas rekam medis mengandung nilai kerahasiaan yang harus dijaga karena didalam rekam medis mengandung riwayat pengobatan pasien dari awal sampai akhir pasientersebut berobat. Maka dari itu rumah sakit berkewajiban menjaga keamanan dan kerahasiaan dokumen rekam medis setiap 
pasien, karena sifat dari dokumen rekam medis adalah rahasia pasien (Sunny, 2008).

Sistem filing adalah salah satu bagian dalam unit rekam medis yang berfungsi menyimpan dokumen rekam medis, penyediaan dokumen rekam medis untuk berbagai keperluan, perlindungan arsiparsip dokumen rekam medis terhadap kerahasiaan isi data rekam medis, perlindungan arsip-arsip dokumen rekam medis terhadap bahaya rusak fisik, kimiawi dan biologi.Sedangkan Permenkes No.269/MENKES/2008 pasal 12 ayat 1 bahwa rekam medis memiliki sarana pelayanan kesehatan, ayat 2 bahwa isi rekam medis merupakan milik pasien, maka rumah sakit berkewajiban untuk menjaga kerahasiaan isi dokumen rekam medis dan memelihara keawetannya (Sunny, 2008).

Keamanan dokumen rekam medis menyangkut dalam bahaya dan kerusakan dokumen rekam medis sendiri.Adapun aspek dari kerusakan yang di maksud meliputi aspek fisik, aspekkimiawi, aspek biologis serta pencurian.Aspek fisik adalah kerusakan dokumen seperti kualitas kertas dan tinta yang disebabkan oleh sinar matahari, hujan, banjir, panas dan kelembaban.Aspek kimiawi adalah kerusakan dokumen yang disebabkan oleh makanan, minuman, dan bahan bahan kimia.Aspek biologis adalah kerusakan dokumen yang di sebabkan oleh tikus, kecoa dan rayap.Sedangkan untuk keamanan isi dari dokumen rekam medis perlu adanya ketentuan peminjaman, dalam peminjaman dokumen rekam medis sehingga dapat diketahui keberadaan dokumen dan siapa peminjamnya, dan juga perlu diketahui juga kepentingan peminjaman dokumen dan harus di perhatikan dari aspek hukumnya (Wijiastuti, 2014).

RSK Paru didirikan pada tahun 1937 oleh Yayasan SCVT (Stiching Centarale Verseninging Voor Tuberculosis Bestanding) perwakilan Indonesia Timur (Gewestelijke Afdeling Sumatera's Oostkust
Van de SCVT ) sebagai sebuah Consultatie Bureau dan klinik paru ( Koningin Emma Kliniek ) dengan ruang perawatan berkapasitas 150 tempat tidur di jalan Perintis Kemerdekaan No. 41 Medan pada areal tanah seluas $\pm 27.000 \mathrm{~m} 2$. yang beralamatkan di Jalan Asrama No. 18 Helvetia Medan.RSK Paru merupakan rumah sakit yang menerima pasien BPJS.

Berdasarkan survei awal dengan menggunakan hasil observasi dan wawancara pada bulan April di RSK Paru yang beralamat di Jalan Asrama No. 18 Kecamatan Helvetia Kota Medan. Keamana an dan kerahasiaan berkas rekam medis di ruang filling belum baik, penulis mendapat kan data pada bulan febuari tahun 2018 ada 2 dokumen yang hilang karena di bawa oleh pasien pulang.

Sering di dapat juga yang mendistribus i dokumen rekam medis adalah pasien tersebut, masih ditemukan beberapa masalah yang berkaitan dengan keamanan dan kerahasiaandokumen rekam medis pasien.RSK Paru tidak memiliki ruang khusus penyimpanan. Berkas banyak berserakan di lantai atau tercecer terutama pada berkas inaktif, pada ruang penyimpanan berkas rekam medis belum ada $\mathrm{AC}$, belum ada alat pemadam api ringan (APAR), belum ada kapur barus(kamper) untuk melindungi berkas rekam medis dari serangan serangga, belum ada peraturan yang ditempelkan secara jelas selain petugas rekam medis dilarang masuk, masih terdapat berkas rekam medis yang berdebu serta penataan berkas rekam medis yang kurang rapi. Dari aspek kerahasiaan pintu tidak di kunci dan masih ada petugas selain rekam medis masuk ke ruang penyimpanan dokumen rekam medis pasien. Berdasarkan latar belakang diatas peneliti tertarik untuk mengangkat judul "Tinjauan aspek keamanan dan kerahasiaan dokumen rekam medis pada ruang filing di Rumah Sakit Khusus Paru Kota Medan Tahun 2018". 


\section{Perumusan Masalah}

Berdasarkan latar belakang di atas yang menjadi rumusan masalah adalah :

1. Bagaimana keamanan dokumen rekam medis dari segi aspek fisik dokumen rekam medis di ruang filling di RSK Paru Kota Medan?

2. Bagaimana keamanan dokumen rekam medis dari segi aspek biologis dokumen rekam medis di ruang filling di RSK Paru Kota Medan?

3. Bagimana keamanan dokumen rekam medis dari segi aspek kimiawi dokumen rekam medis di ruang filling di RSK Paru Kota Medan?

4. Bagaimana kerahasiaan dokumen rekam medis yang ada di ruang filling RSK Paru Kota Medan?

\section{Tujuan Penelitian}

1. Untuk mengetahui keamanan dokumen rekam medis dari segi aspek fisik dokumen rekam medis di ruang filling di RSK Paru.

2. Untuk mengetahui keamanan dokumen rekam medis dari segi aspek biologis dokumen rekam medis di ruang filling di RSK Paru.

3. Untuk mengetahui keamanan dokumen rekam medis dari segi aspek kimiawi dokumen rekam medis di ruang filling di RSK Paru.

4. Untuk mengetahui kerahasiaan dokumen rekam medis yang ada di ruang filling.
Penelitian ini adalah deskriftif kualitatif dengan menggunakan metode observasi. Metode observasi yaitu metode penelitian dengan meninjau langsung objek yang diteliti.

\section{Waktu Dan Tempat Penelitian}

Penelitian ini dimulai pada bulan Maret - Juli 2018.Dilakukan di Rumah Sakit Khusus(RSK) Paru yang beralamat di Jln. Asrama No. 18 Kecamatan Helvetia Kota Medan.

\section{Populasi Dan Sampel}

Populasi dalam penelitian ini adalah dokumenrekam medis yang ada di ruang filling Rumah Sakit Khusus (RSK) Paru Medan mulai dari bulan Maret - Mei tahun 2018 sebanyak 957 dokumen, dan setelah menggunakan rumus makajumlah sampel padapenelitian ini adalah 63 dokumen reka m medis.

\section{Metode Pengumpulan Data}

1. Data Primer.

Data primer diperoleh langsung dari petugas rekam medis dari sumber observasi dan aspek-aspek keamanan dan kerahasiaan dokumen rekam medis.

2. Data Sekunder.

Data sekunder adalah data yang sudah ada yaitu kebijakan prosedur atau Standar Operasional Prosedure (SOP) di RSK Paru. 
1. Editing yaitu hasil wawancara yang diproleh atau dikumpulkan melalui kuesioner perlu disunting (edit) terlebih dahulu.

2. Tabulasi data merupakan proses pengolahan data yang dilakukan dengan cara memasukkan data dalam tabel atau penyajian data yang menguraikan data yang telah dikumpulkan kebentuk kalimat sehingga mudah dipahami.

3. Penyajian data

Suatu cara penglolaan data dengan cara menyajikan hasil dari pengumpulan data berupa narasi.

HASIL

\section{Aspek Fisik}

Tabel 1. Jenis Kertas Dan Tinta Mempengaruhi kemananan Dokumen Rekam Medik

\begin{tabular}{|c|c|c|c|}
\hline \multicolumn{4}{|c|}{ Jenis Kertas } \\
\hline Kertas & $\begin{array}{l}\text { A4 } 70 \mathrm{gr} \\
\text { ( }\end{array}$ & A4 $75 \mathrm{gr}$ & A4 $80 \mathrm{gr}$ \\
\hline Tinta & Hitam & Warna & Pensil \\
\hline
\end{tabular}

Berdasarkan hasil observasi yang dilakukan di RSK Paru Medan, kualitas kertas dan tinta tidak mempengaruhi keamanan dokumen rekam medis.
Tabel 2. Fasilitas Ruangan Mempengaruhi Keamanan Dokumen Rekam Medis Di Ruang Filling RSK Paru Medan.

\begin{tabular}{lll}
\hline Fasilitas Ruangan & & \\
\hline & Ada & Tidak ada \\
\hline AC & \\
Roll o pack & \\
Tracer & \\
Alat Pengukur & \\
Kelembapan suhu & \\
APAR & \\
Kamfer & \\
\hline
\end{tabular}

Dari tabel diatas dapat dilihat bahwa fasilitas filling rekam medis mempengaruhi keamanan dokumen rekam medis yaitu tidak memiliki AC, tracer, alat pengukur kelembapan suhu, APAR dan kamfer .

Tabel 3. Kondisi Ruangan Mempengaruhi Keamanan Dokumen Rekam Medis Di ruang Filling RSK Paru Medan

\begin{tabular}{|c|c|c|}
\hline \multicolumn{3}{|l|}{ Kondisi Ruangan } \\
\hline & Ada & $\begin{array}{l}\text { Tidak } \\
\text { Ada }\end{array}$ \\
\hline $\begin{array}{l}\text { Atap Bocor } \\
\text { Pencahayaan } \\
\text { (Ultraviolet) sinar } \\
\text { matahari yang } \\
\text { langsung jatuh } \\
\text { dipermukaan dokumen } \\
\text { rekam medis }\end{array}$ & (2) & (7) \\
\hline
\end{tabular}

Dari tabel diatas dapat dilihat bahwa kondisi ruangan medis mempengaruhi keamanan dokumen rekam medis yaitu adanya pencahayaan sinar matahari yang langsung jatuh dipermukaan dokumen rekam medis.

Tabel 4. Kelembapan Suhu Mempengaruhi keamanan dokumen rekam medis di ruang filling

\begin{tabular}{lll}
\hline \multicolumn{2}{l}{ Kelembapan Suhu } \\
\hline \multicolumn{2}{c}{ Waktu } & Suhu \\
\hline Pengukuran I & Rabu, 11 juli 2018 & $31,5^{\circ} \mathrm{C}$ \\
Pengukuran II & Kamis 12 juli & $21,7^{\circ} \mathrm{C}$ \\
& 2018 &
\end{tabular}




\begin{tabular}{ll}
\hline Pengukuran & Jum'at 13 juli $2018 \quad 21,3^{\circ} \mathrm{C}$ \\
III
\end{tabular}

Dari tabel diatas dapat dilihat bahwa pengukuran kelembapan suhu yang dilakukan selama 3 kali terdapat perubahan di hari ke 2 dan 3 dimana suhunya $21,7^{\circ} \mathrm{C}$ dan $21,3{ }^{\circ} \mathrm{C}$ suhu normal.

\section{Aspek Biologis}

Tabel 5. Organisme Yang Dapat Mempengaruhi Keamanan Dokumen Rekam Medis Di Ruang Filling RSK Paru Medan.

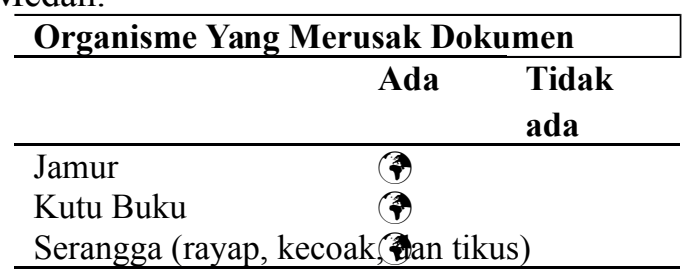

Dari tabel diatas dapat dilihat bahwa jamur, kutu buku dan serangga seperti rayap, kecoa, dan tikus yang terdapat di ruang filling.

\section{Aspek Kerahasiaan Dokumen Rekam Medis di Ruang Filling}

Tabel 7. Kerahasiaan dokumen rekam medis.

\begin{tabular}{lll}
\hline Ancaman & & \\
\hline & Ada & $\begin{array}{l}\text { Tidak } \\
\text { ada }\end{array}$ \\
\hline Selain petugas & \\
rekam medis yang & & \\
masuk ke ruang & & \\
penyimpanan & \\
Dokumen rekam & \\
medis yang dibawa & \\
pasien atau hilang \\
Dokter dan perawat \\
wajib menjaga isi \\
rekam medis
\end{tabular}

Dari tabel diatas dilihat bahwa dokter dan perawat menjaga kerahasian isi rekam medis tidak menjadi penyebab kerahasian dokumen rekam medis, melainkan ada selain petugas rekam medis yang masuk ke ruang penyimpanan dan ada dokumen rekam medis yang dibawa pasien atau hilang.

\section{PEMBAHASAN}

\section{Aspek Kimiawi}

Tabel 6. Bahan-Bahan Kimiawi Mempengaruhi Keamanan Dokumen Rekam Medis Di Ruang Filling RSK Paru Medan

\begin{tabular}{lll}
\hline Ancaman & & \\
\hline & Ada & $\begin{array}{l}\text { Tidak } \\
\text { ada }\end{array}$ \\
\hline Makanan/minuman & & \\
Debu & & \\
\hline
\end{tabular}

Dari tabel diatas dapat dilihat bahwa makanan/minuman dan debu mempengaruh i keamanan dokumen rekam medis.
Berdasarkan hasil penelitian yang dilakukan oleh peneliti faktor yang mempengaruhi keamanan dokumen rekam medis di ruang filling RSK Paru Medan tahun 2018 bagian aspek fisik yang di nilai dari segi kertas, tinta sudah sesuai dengan teori yang ada, dan masih tidak adanya AC melainkan 2 buah kipas angin, kelembapan suhu ruangan yang diukur selama 3 hari rata-rata suhu didalam ruangan sekitar 21,3 - 33,5 ${ }^{\circ} \mathrm{C}$ dengan menggunkan alat bantu pengukur suhu yaitu hygrotermometer, dantidak adanya APAR dan kamfer sehingga kemanan dokumen rekam medis

\section{Aspek Fisik}


belum sesuai dengan teori yang ada. Kondisi ruangan filling rekam medis terletak di depan pintu utama RSK Paru begitu pasien masuk untuk berobat langsung terdapat filling rekam medis yang letaknya tidak di ruangan khusus untuk filling rekam medis sehingga keamanan dokumen rekam medis belum baik.

Aspek fisik adalah kerusakan dokumen seperti kualitas kertas dan tinta yang disebabkan oleh sinar matahari, hujan, banjir, panas dan kelembaban.Bagian fisik formulir terdiri dari bahan, bentuk, ukuran, warna, dan kemasan.Berat bahan kertas harus standar untuk formulir, kertas yang digunakan sebaiknya yang tidak mudah robek dan warnanya cerah untuk berkas rekam medis terdiri dari sampul, formulir dan pembatas formulir.Tentunya sampul menggunakan bahan yang tebal, kemudian ketebalan nomor dua adalah pembatas formulir, kemudian formulir.Bentuk umum format formulir adalah segi empat.Ukuran kertas standar formulir adalah ukuran A4.Warna umum yang digunakan untuk formulir yaitu warna putih.Untuk sampul dan pembatas formulir menggunakan warna cerah.Penggunaan tinta pada tulisan dalam formulir juga perlu diperhatikan untuk kejelasan. Warna pada tinta yang digunakan pada sebagian tulisan juga dapat digunakan sebagai penegasan kalimat tertentu, tinta standar warna hitam (Huffman, 1994).

Ruang penyimpanan jangan terlalu lembab, supaya tidak terlalu lembab dapat dipasang $\mathrm{AC}$ yang hidup 24 jam untuk mengatur kelembapan temperatur udara serta untuk mengurangi banyaknya debu. Pemasangannya harus konstan (tetap), sehingga keadaan udara yang berubah-ubah akan merusakkan kertas, apabila pergantian udara tersebut terjadi secara mendadak. Kelembapan suatu ruang penyimpanan berdasarkan teori berkisar antara $18,8{ }^{\circ} \mathrm{C}$ sampai $24,24{ }^{\circ} \mathrm{C}$ apabila suhu kurang dari normal, maka dalam waktu singkat arsiparsip akan rusak (Wijiastuti, 2014).

Tracer yang digunakan sebagai pengganti berkas rekam medis di rak filling yang dapat digunakan untuk menelusuri keberadaan berkas rekam medis.Ruang harus terang dan sebaiknya menggunakan penerangan yaitu sinar matahari.Sinar matahari memang penting untuk membantu membasmi musuh-musuh kertas.Akan tetapi sinar matahari yang dikarenakan panasnya dan terutama oleh sinar ultraviolet sangat membahayakan bagi kertas-kertas arsip.Oleh karena itu tidak boleh ada sinar yang jatuh langsung ke bundel-bundel kertas ataupun pada kertasnya sendiri. Pengamanan dari kemungkinan serangan api atau kebakaran ini bisa saja terjadi dari kondisi ruangan yang kurang baik. Karena serangan api bisa saja melalui kabel listrik yang korslet sehingga dapat menyebabkan kebakaran (Wijiastuti, 2014).

\section{Aspek Biologis}

Berdasarkan hasil penelitian yang dilakukan oleh peneliti masih banyak ditemukan kecoa dan tikus pada rekam medis di rak filling, ini disebabkan karena tidak diberinya kamper dan kondisi kelembapan ruanganyang berubah-ubah setiap harinya.

Aspek biologis yang kerap merusak DRM antara lain yaitu jamur merupakan bukti temperatur udara yang tidak terkontrol, kegiatan jamur sangat cepat karena jamur hidup dari pada perekat yang berada pada kertas, upaya menghindarinya adalah dengan menempatkan DRM ditempat yang kering, terang dan ruangan yang berventilasi senpurna, kutu buku sering merusak buku, jika kertas selalu tersentuh dengan dinding yang lembab, bukan saja kertas menjadi lembab, akan tetapi sering pula diserang kutu buku untuk menghindarinya digunakan rak yang menempel dengan dinding dipasang antara lain 6 inci dari dinding. Usaha untuk menghindari serangan seperti rayap, kecoak, dan tikus adalah dengan mengadakan pencegahan yakni peniadaan kayu yang langsung dengan tanah, diberikan kamferpada setiap rak untuk 
menghindari serangan serangga (Wijiastuti, 2014).

\section{Aspek Kimiawi}

Berdasarkan hasil penelitian masih terdapat petugas rekam medis makan dan minum di ruangan rekam medik, apabila mengandung minyak akan menempel dan menjadi kotor sehingga mengakibatkan dokumen rekam medis menjadi rusak.

Aspek Kimiawi yaitu kerusakan arsip yang lebih diakibatkan oleh merosotnya kualitas kandungan bahan kimia dari bahan arsip, seperti penggunaan tinta yang berkualitas tidak mungkin luntur, sedangkan penggunaan tinta yang berkualitas rendah akan merusak dan melunturi kertas bila sengaja tersentuh air atau udara yang lembab. Selain itu, makanan dan minuman juga dapat mempengaruhi kerusakan DRM, karena apabila makanan dan minuman tersebut, mengandung minyak akan menempel dan menjadi kotor, bahan kimia yang terkandung dalam makanan dan minuman tersebut juga dapat merusak kertas (Setyowati, 2013).

\section{Aspek Kerahasiaan Dokumen Rekam Medis.}

Berdasarkan hasil penelitian masih banyak terdapat selain petugas rekam medis masuk ke ruang filling, terdapat dokumen rekam medis yang di bawa pasien/hilang.

Rekam medis berisifat rahasia, artinya tidak semua orang bisa membaca dan mengetahuinya. Dalam pasal 10 ayat 1 Permenkes 269/Menkes/III/2008 mengatakan bahwa informasi tentang identitas, diagnosis, riwayat penyakit, riwayat pemeriksaan dan riwayat pengobatan pasien harus dijaga kerahasiaannya oleh dokter, dokter gigi, tenaga kesehatan tertentu, petugas pengelola dan pimpinan sarana pelayanan kesehatan.

Informasi tentang identitas, diagnosis, riwayat penyakit, riwayat pemeriksaan dan riwayat pengobatan dapat dibuka dalam hal:

a. Untuk kepentingan kesehatan pasien.

b. Memenuhi permintaan aparatur penegak hukum dalam rangka penegakan hukum atas perintah pengadilan.

c. Permintaan dan/atau persetujuan pasien sendiri.

d. Permintaan institusi/lembaga berdasarkan ketentuan perundangundangan.

e. Untuk kepentingan penelitian, pendidikan, dan audit medis sepanjang tidak menyebutkan identitas pasien.

Tanpa adanya izin tertulis dari pasien, dokter/ dokter gigi tidak boleh memberikan penjelasan tentang rekam medis kepada publik.Setiap dokter wajib merahasiakan segala sesuatu yang diketahuinya tentang seorang pasien, bahkan juga setelah seorang pasien itu telah meninggal dunia.

Bab IV butir 2 Keputusan DIRJEN Pelayanan Medik Nomor : 78/Yanmed/ RS.UM.DIK/YMU/I/91 tentang petunjuk pelaksanaan penyelenggaraan rekam medik/Medical Recorddi rumah sakit, yang berbunyi :" Isi rekam medis adalah milik pasien yang wajib dijaga kerahasiaannya". Untuk melindungi kerahasiaannya tersebut, maka dibuat ketentuan sebagai berikut:

a. petugas rekam medis yang diijinkan masuk penyimpanan berkas rekam medis. 
b. Dilarang mengutip sebagian atau seluruh isi rekam medis untuk badanbadan atau perorangan, kecuali yang telah ditentukan oleh peraturan perundang-undangan yang berlaku.

c. Selama penderita dirawat, rekam medis menjadi tanggung jawab perawat ruangan dan menjaga kerahasianny (Sunny, 2008)

\section{KESIMPULAN}

\section{Aspek Fisik}

Aspek fisik yang terdapat di RSK Paru dari segi kertas dan tinta sudah baik dan masih terdapat kelembapan suhu yang berubah-ubah dan tidak terdapat AC, tracer, APAR dan kamfer

\section{Aspek Biologis}

Aspek biologis yang terdapat di RSK Paru yaitu masih adanya jamur, kutu buku, dan serangga seperti rayap, kecoa, dan tikus.

\section{Aspek Kimiawi}

Aspek kimiawi yang terdapat di RSK Paru yaitu dari segi makanan/minuman dan debu, masih ditemukan petugas rekam medis yang makan dan minum di ruang rekam medis.

\section{Aspek Kerahasiaan}

Aspek kerahasiaannya belum terjaga dengan baik, karena diruang penyimpanan masih banyak lalu lalang selain petugas rekam medis.pendistribusian tidak baik, karena pasien yang mendistribusi dokumen rekam medis.

\section{SARAN}

\section{Aspek Fisik}

Sebaiknya ruang penyimpanan dokum en rekam medis dapat dipasang $\mathrm{AC}$ yang hidup 24 jam untuk mengatur kelembapan temperatur udara serta untuk mengurangi banyaknya debu. Dapat juga disediakan APAR (Alat Pemadam Api Ringan) untuk pencegahan adanya kebakaran dan tracer sebagai pengganti berkas rekam medis di rak filling yang dapat digunakan untuk menelusuri keberadaan berkas rekam medis.

\section{Aspek Biologis}

Sebaiknya dilakukan pemeliharaan kebersihan diruang penyimpanan dokumen rekam medis, seperti dilakukan penyemprot an serangga atau diberi kamper pada ruang penyimpanan.

\section{Aspek Kimiawi}

Sebaiknya petugas rekam medis tidak makan dan minum di ruangan rekam medis agar keamanan dokumen rekam medis terjaga dengan baik.

\section{Aspek Kerahasiaan}

Dokumen rekam medis pasien yang keluar dari penyimpanan diantarkan oleh petugas distribusi, selain petugas rekam medis dilarang masuk ke ruang rekam 
medis dan pintu rekam medis sebaiknya hanya 1 agar kerahasiaannya tetap terjaga. Adanya alat pengantar status disediakan dalam bentuk tertutup, dan petugas distribusi menggunkan buku ekspedisi.

\section{DAFTAR PUSTAKA}

Arikunto.(2010). Prosedur Penelitian Suatu Pendekatan Praktik.Jakarta : Rineka Cipta.

Budi, Citra Savitri. (2011). Manajemen Unit Kerja Rekam Medis. Yogyakrta: Quantum Sinergis Media.

Firdaus, Ummul Sunny. (2008). Rekam Medik Dalam Sorotan Hukum dan Etika Cetakan 1. Surakrta:LPP UNS dan UNS Press.

Hatta, G. R (2014).Manajemen Informasi Kesehatan di Sarana Pelayanan kesehata. Jakarta:UIPress.

Notoatmodjo, Soekidjo. (2010). Metodologi Penelitian Kesehatan. Jakarta: Rineka Cipta.
Prasasti, Intan Tazia. (2017). Keamanan dan Kerahasiaan Berkas Rekam Medis di RSUD Dr. Soehadi Prijonegoro Sragen. Diakses Mei 2018. https://jurnal.ugm.ac.id/jkesvo

Rustiyanto, Ery. (2009). Etika Profesi ; Perekam Medis Dan Informasi Kesehatan. Yogyakarta:Graha Ilmu.

Saryono, (2013).Metodologi Penelitian Kesehatan. Yogyakarta: Nuha Medika.

Setyowati, Maryani. (2013). Tinjauan Aspek Keamanan Dokumen Rekam Medis Di Ruang Filling Puskesmas Lebdosari Semarang. Diakses Juni 2018.

https://publikasi.dinus.ac.id/index.php/ visikes/article/view/647.

UU Republik Indonesia NO.44 Tahun 2009 tentang rumah sakit.

Wijiastuti, Novia. (2014). Tinjauan Pelaksanaan Pemeliharaan Dokumen Rekam Medis di Ruang Filling Rawat Inap RSUD Sunan Kalijaga. Demak. Diakses Juli 2018

http://eprints.dinus.ac.id/6680/1/jurnal 13820.pdf. 
